\title{
An Assessment Model of National Grants of University Based on Fuzzy Analytic Hierarchy Process
}

\author{
Yang XIA ${ }^{1}$,Cheng-Gang JIANG ${ }^{2}$ \\ ${ }^{1}$ Student Affairs Office, Suzhou University of Science and Technology, Suzhou 215009, P. R. China \\ 2 Youth League Committee, Suzhou University of Science and Technology, Suzhou 215009, P. R. China
}

\begin{abstract}
How to assess kinds of grants scientifically, effectively and regularly is an important topic for the funding workers to study. According to the national grants' basic conditions, an assessment model is established on the basis of fuzzy analytic hierarchy process. And Finally an example is given to illustrate the scientificalness and operability of this model.
\end{abstract}

\section{Introduction}

China has established a fairly perfect student financial assistance policy system, covering from preschool to graduate education, particularly in higher education which has national scholarships, student loans, tuition reimbursement compensatory loans, school scholarships, work-study subsidies, difficult subsidies, food subsidies, tuition waiver, "green channel" and other mixed funding systems. How to put these funding initiatives in place scientifically, effectively and normatively has become an important subject of workers who focus on funding in universities. Some domestic scholars use the AHP to make a study of the identification system of students from poor families [1] and the evaluation system of state grants [2]. Because it is difficult to test the consistency of judging matrix in the Analytic Hierarchy Process, consistency test of judging matrix is often achieved by the constant adjustments according to the subjective factors of the decision-makers during the specific implementation processes. The author has studied the identified evaluation about university students from poor families using the Fuzzy Analytic Hierarchy Process [3]. In order to further strengthen the research results, ensure that state stipend is given fairly and reasonably, and enhance the scientific and normative work of university funding, the author will use the fuzzy analytic hierarchy process to model the assessment of state stipend for colleges and universities, and provide quantitative and feasible approaches for the university funding workers.

\section{The Current Problems of National Grants in Colleges and Universities}

According to The tentative Management Method of National Grants in General Undergraduate Colleges and
Higher Vocational Colleges (The finance and education[2007]NO.92), the basic application conditions of national grants are as follow: (1) Deep love for socialist motherland and advocacy of Chinese Communist Party; (2) Compliance with constitution, law and school regulations; (3) Honesty, trustworthiness, and good moral quality. (4) Study diligently and be positive; (5)Having economical difficulties with family. Based on this, the universities have also developed a corresponding assessment rules. But in view of the versatility of the basic conditions and evaluation work still confronts with some objective difficulties. For example, how to evaluate (4) and (5) in the basic condition? And how to stable the student who apply for the national student financial aid? It's obvious that the evaluation of the state grants is a multi-level, multi factor comprehensive evaluation problems. If the single factor is under evaluation, the fairness of education can't be ensured and many indicators cannot be analyzed by normal mathematical methods.

\section{The Basic Principles of Fuzzy Analytic Hierarchy Process}

Fuzzy Analytic Hierarchy Process [4] is a kind of idea and method, which is established by introducing fuzzy mathematics to the Analytic Hierarchy Process. It means to make improvements in Analytic Hierarchy Process because the judging matrix is much difficult to achieve and evaluate the matrix's consistency and the differences of decision making. And it is a useful and efficient decision making way that through setting up an optimized hierarchy structure model, constructing a prioritized matrix. All in all, the Fuzzy Analytic Hierarchy Process is a combination of Fuzzy Analytic Process and Analytic Hierarchy Process. In the sequel, 
we will introduce the basic principles and the basic steps of Fuzzy Analytic Hierarchy Process

\subsection{The Basic Knowledge of Fuzzy Analytic Hierarchy Process}

Definition 1 ([5]) If the matrix $\boldsymbol{R}=\left(r_{i j}\right)_{n \times n}$ satisfies $0 \leq r_{i j} \leq 1, i, j=1,2, \cdots, n$, then $\boldsymbol{R}$ is called the analytic hierarchy process.

Definition 2 ([5]) If the matrix $\boldsymbol{R}=\left(r_{i j}\right)_{n \times n}$ satisfies $r_{i j}+r_{j i}=1, i, j=1,2, \cdots, n$, then $\boldsymbol{R}$ is called the fuzzy reciprocal matrix.

Definition 3 ([6]) If the fuzzy reciprocal matrix $\boldsymbol{R}=\left(r_{i j}\right)_{n \times n} \quad$ satisfies $\quad r_{i j}=r_{i k}-r_{j k}+0.5$ for any $k$, then $\boldsymbol{R}$ is called the fuzzy consistent matrix.

Theorem 1 ([7]) Let the fuzzy reciprocal matrix $\boldsymbol{R}=\left(r_{i j}\right)_{n \times n} \quad$ sum up with lines, denoting as $f_{i}=\sum_{k=1}^{n} r_{i k} \quad, \quad$ and use the transformation $f_{i j}=\frac{r_{i}-r_{j}}{2 n}+0.5 \quad$, then we can get the fuzzy consistent matrix $\mathbf{F}=\left(f_{i j}\right)_{n \times n}$.

\subsection{The Basic Steps of Fuzzy Analytic Hierarchy Process}

There are four steps to model with Analytic Hierarchy Process: setting up a hierarchy structure model, constructing a judging matrix, ordering in single hierarchy, and ranking in general hierarchy. Compared to Analytic Hierarchy Process, Fuzzy Analytic Hierarchy Process has made improvements in its consistency of judging matrix. Therefore, the steps of modeling of Fuzzy Analytic Hierarchy Process are similar to those of Analytic Hierarchy Process: setting up an optimized hierarchy structure model, constructing a prioritized matrix, creating an optimized relation hierarchy, building a fuzzy consistency hierarchy, and ranking both in single hierarchy and general hierarchy.

\section{The Construction of the Assessment Model of National Grants of University Based on Fuzzy Analytic Hierarchy Process}

Being multi-leveled and multi-factored, the assessment of national grants for financially disadvantaged university students turns out to be comprehensive. At the same time, the assessment has its root in both quantity analysis and quality analysis. Therefore, this section will follow the basic steps of fuzzy analytic hierarchy process to build up an assessment model of national grants of university.

\subsection{Constructing A Prioritized Matrix}

First of all, the complicated problem should be grouped into several multi-elements parts by the standard of essential requirements. Then, those elements need to be classified into smaller groups to form various hierarchies. As criteria, those elements not only have an influence on the next hierarchy, but also are affected by the former hierarchy. This top-down structure establishes a prioritized matrix.

Secondly, according to the essential requirements of the assessment of national grants of university, factor set $\mathrm{A}$ is created:

$$
A=\left\{A_{1}, A_{2}, A_{3}, A_{4}\right\}=\{\text { moral performance, }
$$
academic record, family background, consumption level\}.

And the subsets are:

$A_{1}=\left\{A_{11}, A_{12}\right\}=\{$ excellent, favorable $\}$, the moral performance aims at evaluating the first three essential requirements;

$$
A_{2}=\left\{A_{21}, A_{22}, A_{23}\right\}=\text { excellent, favorable, }
$$

qualified $\}$, the academic record aims at evaluating the fourth essential requirement. Being excellent means the student ranks among the first third in the whole class; being favorable means the student ranks between the first third and the second third; being qualified means the student studies hard and never fails in any exam;

$$
A_{3}=\left\{A_{31}, A_{32}, A_{33}\right\}=\text { averagely disadvantaged, }
$$
disadvantaged, and relatively disadvantaged $\}$;

$$
A_{4}=\left\{A_{41}, A_{42}, A_{43}\right\}=\{\text { up to the average level }
$$
of consumption, slightly below the average level of consumption, far below the average level of consumption $\}$.

All the sets of factors above use both quantity analysis and quality analysis to build up a system of the assessment factors of the national grants of university (see Table 1). In this way, the precision of the

\begin{tabular}{|c|c|c|}
\hline $\begin{array}{c}\text { Destination } \\
\text { Layer A }\end{array}$ & $\begin{array}{l}\text { Criterion } \\
\text { Layer B }\end{array}$ & Criterion Layer C \\
\hline \multirow{11}{*}{$\begin{array}{c}\text { The } \\
\text { System of } \\
\text { the } \\
\text { Assessme } \\
\text { nt Factors } \\
\text { of the } \\
\text { National } \\
\text { Grants of } \\
\text { University }\end{array}$} & \multirow{2}{*}{$\begin{array}{c}\text { Moral } \\
\text { Performanc } \\
\mathrm{e} \\
\end{array}$} & Excellent \\
\hline & & Favorable \\
\hline & \multirow{3}{*}{$\begin{array}{l}\text { Academic } \\
\text { Record }\end{array}$} & Excellent \\
\hline & & Favorable \\
\hline & & qualified \\
\hline & \multirow{3}{*}{$\begin{array}{c}\text { Family } \\
\text { Background }\end{array}$} & Averagely Disadvantaged \\
\hline & & Disadvantaged \\
\hline & & Relatively Disadvantaged \\
\hline & \multirow{3}{*}{$\begin{array}{l}\text { Consumption } \\
\text { Level }\end{array}$} & $\begin{array}{c}\text { Up to the Average Level of } \\
\text { Consumption }\end{array}$ \\
\hline & & $\begin{array}{c}\text { Slightly Below the Average } \\
\text { Level of Consumption }\end{array}$ \\
\hline & & $\begin{array}{c}\text { Far Below the Average Level } \\
\text { of Consumption }\end{array}$ \\
\hline
\end{tabular}
assessment can be improved

Table 1 The System of the Assessment Factors of the National Grants of University 


\subsection{Setting up Prioritized Relation Matrix}

After priority hierarchy has been established, subordinate relationship between each level (which can use $\leftarrow$ to show the relationship) is clear. The author divided the importance of evaluation standards with assistance of the Satty 9 degree scale [8] (shown in the table 2) and quantified the complicated evaluation of National grants which are influenced by multi-elements and multi-levels and combined with quality and quantity.

Table 2 The Definition of Satty 9 Degree Scale

\begin{tabular}{|c|c|c|}
\hline scale & definition & explanation \\
\hline 0.5 & $\begin{array}{l}\text { Equally } \\
\text { important }\end{array}$ & $\begin{array}{l}\text { Comparing two factors, they } \\
\text { are equally important }\end{array}$ \\
\hline 0.6 & $\begin{array}{l}\text { A little } \\
\text { more } \\
\text { important }\end{array}$ & $\begin{array}{l}\text { Comparing two factors, one is } \\
\text { a little more important than } \\
\text { the other }\end{array}$ \\
\hline 0.7 & $\begin{array}{l}\text { Apparently } \\
\text { more } \\
\text { important }\end{array}$ & $\begin{array}{l}\text { Comparing two factors, one is } \\
\text { apparently more important } \\
\text { than the other }\end{array}$ \\
\hline 0.8 & $\begin{array}{l}\text { Much more } \\
\text { important }\end{array}$ & $\begin{array}{l}\text { Comparing two factors, one is } \\
\text { much more important than the } \\
\text { other }\end{array}$ \\
\hline 0.9 & $\begin{array}{l}\text { extre } \\
\text { impc }\end{array}$ & $\begin{array}{l}\text { Comparing two factors, one is } \\
\text { extremely important }\end{array}$ \\
\hline $\begin{array}{l}0.1 \\
0.2 \\
0.3 \\
0.4\end{array}$ & $\begin{array}{l}\text { Comparison } \\
\text { on the } \\
\text { contrary }\end{array}$ & $\begin{array}{l}\text { comparing } a_{i} \text { and } a_{j} \text {, } \\
\text { judging } b_{j i} \\
\text { comparing } a_{j} \text { and } a_{i} \text {, then } \\
\text { judging } b_{j i}=1-b_{i j}\end{array}$ \\
\hline
\end{tabular}

According to the method, the above-mentioned prioritized relation matrices are as follows.

$$
\begin{gathered}
\mathbf{A} \leftarrow \mathbf{A}_{i}=\left[\begin{array}{llll}
0.5 & 0.7 & 0.3 & 0.2 \\
0.3 & 0.5 & 0.4 & 0.3 \\
0.7 & 0.6 & 0.5 & 0.9 \\
0.8 & 0.7 & 0.1 & 0.5
\end{array}\right], \mathbf{A}_{1} \leftarrow \mathbf{A}_{11}=\left[\begin{array}{ll}
0.5 & 0.8 \\
0.2 & 0.5
\end{array}\right], \mathbf{A}_{2} \leftarrow \mathbf{A}_{21}=\left[\begin{array}{lll}
0.5 & 0.7 & 0.9 \\
0.3 & 0.5 & 0.7 \\
0.1 & 0.3 & 0.5
\end{array}\right], \\
\mathbf{A}_{3} \leftarrow \mathbf{A}_{3 \mathrm{i}}=\left[\begin{array}{lll}
0.5 & 0.2 & 0.3 \\
0.8 & 0.5 & 0.1 \\
0.7 & 0.9 & 0.5
\end{array}\right], \mathbf{A}_{4} \leftarrow \mathbf{A}_{4 i}=\left[\begin{array}{lll}
0.5 & 0.3 & 0.1 \\
0.7 & 0.5 & 0.3 \\
0.9 & 0.7 & 0.5
\end{array}\right] .
\end{gathered}
$$

\subsection{Setting up Fuzzy Consistent Matrix}

According to Definition 1 and Definition 2, the above prioritized relation matrix are all fuzzy reciprocal matrix, and form the following fuzzy consistent matrix of Theorem 1 .

$$
\begin{aligned}
& \mathbf{F} \leftarrow \mathbf{F}_{\mathbf{i}}=\left[\begin{array}{cccc}
0.5 & 0.525 & 0.375 & 0.45 \\
0.475 & 0.5 & 0.35 & 0.425 \\
0.625 & 0.65 & 0.5 & 0.575 \\
0.55 & 0.575 & 0.425 & 0.5
\end{array}\right], \mathbf{F}_{1} \leftarrow \mathbf{F}_{1 \mathrm{i}}=\left[\begin{array}{cc}
0.5 & 0.575 \\
0.425 & 0.5
\end{array}\right], \mathbf{F}_{2} \leftarrow \mathbf{F}_{2 \mathrm{i}}=\left[\begin{array}{ccc}
0.5 & 0.6 & 0.7 \\
0.4 & 0.5 & 0.6 \\
0.3 & 0.4 & 0.5
\end{array}\right], \\
& \mathbf{F}_{3} \leftarrow \mathbf{F}_{3 \mathrm{i}}=\left[\begin{array}{ccc}
0.5 & 0.433 & 0.317 \\
0.567 & 0.5 & 0.383 \\
0.683 & 0.617 & 0.5
\end{array}\right], \mathbf{F}_{4} \leftarrow \mathbf{F}_{4 \mathrm{i}}=\left[\begin{array}{lll}
0.5 & 0.4 & 0.3 \\
0.6 & 0.5 & 0.4 \\
0.7 & 0.6 & 0.5
\end{array}\right] .
\end{aligned}
$$

According to Definition 3, it's easy to prove that these matrixes are fuzzy consistent matrix.

\subsection{Ranking}

\subsubsection{Ranking in Single Hierarchy}

Ranking in single hierarchy is to calculate the corresponding feature vectors according to the above fuzzy consistent matrix. And their corresponding weight values are as follows. (The computing method of the weight values could be seen in ref.3, the calculation process is omitted here.)

$\mathbf{w}=\{0.2310,0.2183,0.2943,0.2563\}, \mathbf{w}_{1}=\{0.5377,0.4623\}, \mathbf{w}_{2}=\{0.4019,0.333,0.2648\}$,

$$
\mathbf{w}_{3}=\{0.2765,0.3219,0.4016\}, \mathbf{w}_{4}=\{0.2648,0.333,0.4019\} .
$$

$$
\begin{aligned}
& \text { 3.4.2 Ranking in General Hierarchy } w_{i j} \\
& \left(w_{i j}=A_{i j} \times A_{i}, i=1,2,3,4 ; j=1,2,3\right)
\end{aligned}
$$

Table 3 Comprehensive weight values

\begin{tabular}{|c|c|c|c|c|c|}
\hline & $A_{1}$ & $A_{2}$ & $A_{3}$ & $A_{4}$ & \multirow{2}{*}{$w_{i j}$} \\
\cline { 2 - 5 } & 0.2310 & 0.2183 & 0.2943 & 0.2563 & \multirow{2}{*}{} \\
\hline$A_{11}$ & 0.5377 & & & & 0.1242 \\
\hline$A_{12}$ & 0.4623 & & & & 0.1068 \\
\hline$A_{21}$ & & 0.4019 & & & 0.0877 \\
\hline$A_{22}$ & & 0.333 & & & 0.0727 \\
\hline$A_{23}$ & & 0.2648 & & & 0.0578 \\
\hline$A_{31}$ & & & 0.2765 & & 0.0814 \\
\hline$A_{32}$ & & & 0.3219 & & 0.0947 \\
\hline$A_{33}$ & & & 0.4016 & & 0.1182 \\
\hline$A_{41}$ & & & & 0.2648 & 0.0679 \\
\hline$A_{42}$ & & & & 0.333 & 0.0853 \\
\hline$A_{43}$ & & & & 0.4019 & 0.1030 \\
\hline
\end{tabular}

According to the table 3 , it concludes that in the aspect of relative importance of each factors in $A=\left\{A_{1}, A_{2}, A_{3}, A_{4}\right\} \quad, \quad$ family background, consumption level, the moral performance and the academic records in turn rank in the first-degree factors that influence evaluation of national grants, which indicates that students financial disadvantaged are major beneficiaries of national grants. It fits in with the intention of funds. Meanwhile, the grade two requires high standard in conduct, which also shows that the destination of the national grants is to educate people and matches the national financial aid policies. Surely, moral performance, consumption level and the academic records also make their corresponding difference in the grade two factors.

\section{Example and conclusion}

Take an example of four students, Zhang, Wang, Li, 
Qian. According to available evaluation factors, people in charge of evaluation can effectively evaluate these

\begin{tabular}{|c|c|c|c|c|c|c|}
\hline Destination Layer A & Criterion Layer B & Criterion Layer C & Zhang & Wang & $\mathrm{Li}$ & Qian \\
\hline \multirow{11}{*}{$\begin{array}{l}\text { The System of the Assessment } \\
\text { Factors of the National Grants of } \\
\text { University }\end{array}$} & \multirow{2}{*}{ Moral Performance } & excellent & & $\sqrt{ }$ & & $\sqrt{ }$ \\
\hline & & Favorable & $\sqrt{ }$ & & $\sqrt{ }$ & \\
\hline & \multirow{3}{*}{ Academic Record } & excellent & & $\sqrt{ }$ & & \\
\hline & & Favorable & $\sqrt{ }$ & & & \\
\hline & & qualified & & & $\sqrt{ }$ & $\sqrt{ }$ \\
\hline & \multirow{3}{*}{ Family Background } & Averagely Disadvantaged & $\sqrt{ }$ & & & \\
\hline & & Disadvantaged & & $\sqrt{ }$ & & \\
\hline & & Relatively Disadvantaged & & & $\sqrt{ }$ & $\sqrt{ }$ \\
\hline & \multirow{3}{*}{ consumption level } & $\begin{array}{l}\text { Up to the Average Level of } \\
\text { Consumption }\end{array}$ & & & & $\sqrt{ }$ \\
\hline & & $\begin{array}{l}\text { Slightly Below the } \\
\text { Average Level of } \\
\text { Consumption } \\
\end{array}$ & $\sqrt{ }$ & & & \\
\hline & & $\begin{array}{l}\text { Far Below the Average } \\
\text { Level of Consumption }\end{array}$ & & $\sqrt{ }$ & $\sqrt{ }$ & \\
\hline
\end{tabular}

For the convenience of calculation, we assume that all marked checks are assigned the value 1 and the rest the value 0 . In that case, a matrix $\mathbf{D}$ can be got as follows.

$\mathbf{D}=\left[\begin{array}{l}0 \\ 1 \\ 0 \\ 1 \\ 0 \\ 1 \\ 0 \\ 0 \\ 0 \\ 1 \\ 0\end{array}\right.$

At the same time, having

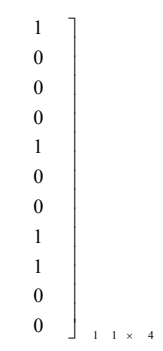

hundredfold, choosing their approximate numbers and taking calculation

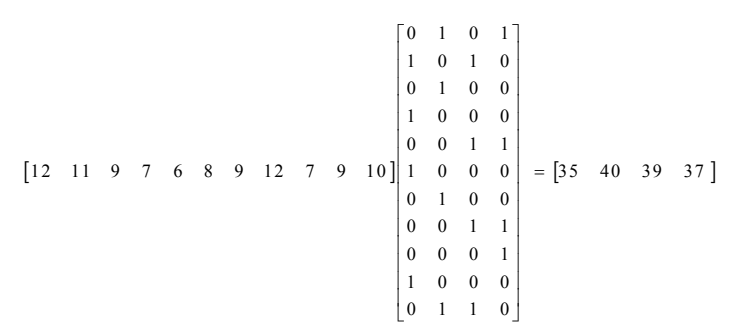

Among them, the four numerical values [35 4039 37] correspondingly refer to the comprehensive values of four students, Zhang, Wang, Li, Qian. Through analyzing the statistics, it is found that Wang is less financially disadvantaged than $\mathrm{Li}$ but Wang scores higher than $\mathrm{Li}$, which is for the reason that the former moral performance and academic records are better than the latter ones. Comparing with $\mathrm{Li}$ and Qian, their family economies nearly reach the same level. However, their different consumption levels lead to their different scores. The scientific evaluation towards applicants can finally decide which level of the financial aids they can approved to gain. This above mentioned examples illustrates that the model has a strong operation and four applicants. The result of evaluation is shown in

table 4.

four applicants 
of Suzhou University of Science and Technology (Natural Science), 32:11-13(2015). (in Chinese)

4. J.J. Wang, Group Fuzzy Analytical Hierarchy Process Based on the 0-1 Programming. Fuzzy Systems and Mathematics, 29: 117-125(2015). (in Chinese)

5. L.K. Jiang,The Fuzzy Consistent Matrix Applied in Analytic Hierarchy Process. Journal of Shanghai Maritime University, 19: 55-60(1998). (in Chinese)

6. M. Yao, S. Zhang,Fuzzy Consistent Matrix and Its Application in Decision making. Systems Engineering Theory\& Practice, 5: 78-81(1998). (in Chinese)

7. X.Chen, Application of Fuzzy Analytic Hierarchy Process for Optimum Selection in Decision-making. Computer Engineering and Design, 25: 1847-1849(2004). (in Chinese)

8. J.J. Zhang, Fuzzy Analytical Hierarchy Process. Fuzzy Systems and Mathematics, 14: 80-88(2000). (in Chinese) 